\title{
ENGENHARIA DO PRODUTO PARA EXPORTAÇÃO: \\ O CASO DA MADEIREIRA X DA CIDADE DE PONTA GROSSA - PR
}

\section{EXPORTATION PRODUCT ENGINEERING: \\ THE CASE OF X WOOD COMPANY IN THE CITY OF PONTA GROSSA - PR}

\section{Arquimedes da Silva Szezerbicki}

Centro de Estudo Superior dos Campos Gerais (CESCAGE) e Universidade Tecnológica Federal do Paraná (UTFPR)- Unidade de Ponta Grossa

Professor do CESCAGE e Mestrando no Programa de Pós-Graduação em Engenharia de Produção da UTFPR.

(42) 9919-1907

Rua Coronel Bittencourt, no 484 - 84010-290 - Ponta Grossa - Paraná szezerbicki@uol.com.br

\section{Luiz Alberto Pilatti, Dr}

Universidade Tecnológica Federal do Paraná (UTFPR) Unidade de Ponta Grossa

Professor do Programa de Pós-Graduação em Engenharia da Produção da UTFPR

(42) $3220-4805$

Av. Monteiro Lobato, s/n. - Km 4 - 84016-210 - Ponta Grossa - Paraná

lapilatti@pg.cefetpr.br

\section{João Luiz Kovaleski, Dr}

Universidade Tecnológica Federal do Paraná (UTFPR) Unidade de Ponta Grossa

Professor do Programa de Pós-Graduação em Engenharia da Produção da UTFPR

$$
\text { (42) 3220-4805 }
$$

Av. Monteiro Lobato, s/n. - Km 4 - 84016-210 - Ponta Grossa - Paraná

kovaleski@pg.cefetpr.br

\section{Antônio Carlos de Francisco}

Universidade Tecnológica Federal do Paraná (UTFPR) Unidade de Ponta Grossa

Professor do Programa de Pós-Graduação em Engenharia da Produção da UTFPR

(42) 3220-4805

Av. Monteiro Lobato, s/n. - Km 4 - 84016-210 - Ponta Grossa - Paraná

acfrancisco@terra.com.br 


\title{
Resumo
}

Este trabalho apresenta uma pesquisa de campo em uma Madeireira, situada na cidade de Ponta Grossa, no estado do Paraná que, a partir de 2000, passou a produzir dois produtos denominados "clear blocks" e "blanks", destinados exclusivamente à exportação, sendo, no mercado interno, vendidos apenas os subprodutos do processo. Houve, então, uma mudança no perfil da produção, devido à aquisição da máquina "Finger joint", específica para a execução de uma das mais importantes etapas do beneficiamento da madeira. Assim, este estudo mostra como a Engenharia do Produto é importante para o crescimento de uma empresa, que de uma pequena madeireira, passou, em pouco tempo, a uma expressiva exportadora.

Palavras-chave: Produto, Exportação, Finger joint.

\begin{abstract}
This paper features a field research in a Wood Company located in the city of Ponta Grossa, State of Paraná, which from 2000 on started producing two items named "clear blocks" and "blanks". They were exclusively destined to exportation and in the internal market only the sub products, which resulted from the process, were sold. Then, there was a change in the production profile due to the acquisition of the "Finger joint" machine, which is specific for the achievement of one of the most important stages in wood benefaction. Thus, this study shows how Product Engineering is important for the growth of a company, which was small and turned out to be an important exportation corporation.
\end{abstract}

Key words: Product, Exportation, Finger joint.

\section{Introdução}

À medida que as organizações de sucesso têm crescido em tamanho, diversidade e dispersão geográfica, cresce também a tendência de observar as oportunidades que existem em outros países. E isso não ocorre apenas com as grandes organizações.

Com o advento da globalização, pequenos empreendimentos mostram-se em franca expansão para a exportação de produtos. Para isso, precisam buscar produtos diferenciados e com alta qualidade, para conseguirem seu lugar num mercado tão exigente como o internacional. 
Entretanto, importante se faz a conscientização de que exportar não pode ser caracterizado como um acontecimento isolado no desenvolvimento empresarial. "Trata-se de uma atividade que se desenvolve paralelamente aos demais compromissos representativos da vida econômica, significando o perfeito entrosamento da nova investida com aquelas operações regularmente desenvolvidas." (GARCIA, 2001, p. 25).

A colocação acima é necessária devido ao fato de que a exportação não pode ser considerada no contexto empresarial como uma empreitada meramente acidental, impondo dedicação apenas enquanto o mercado interno não se apresenta promissor para os produtos que compõem o dia a dia da empresa.

Para Garcia, "relegar a exportação a plano secundário no rol de acontecimentos da atividade econômica significa atestar que não conseguimos adequar o ambiente empresarial ao perfeito entrosamento dessa operação" (2001, p. 25). Nota-se, então, que exportar somente os excedentes equivale à ausência de empenho para a sedimentação empresarial podendo mesmo ser caracterizado como comportamento retrógrado.

Vê-se, neste ínterim, que o sucesso da empresa no mercado internacional depende essencialmente da Engenharia do Produto, ou seja, pontos como a qualidade, disponibilidade, diferenciação, são muito visados.

Portanto, a problemática que envolve o objeto de análise da presente pesquisa busca analisar a importância da Engenharia do produto para as exportações. Assim sendo, este trabalho apresenta uma pesquisa de campo em uma Madeireira - aqui representada pelo nome fictício "Madeireira X" -, situada na cidade de Ponta Grossa, no estado do Paraná, que a partir de 2000 passou a produzir dois produtos denominados "clear blocks" e "blanks", destinados exclusivamente à exportação, sendo, no mercado interno, vendidos apenas os subprodutos do processo. Houve, então, uma mudança no perfil da produção, devido à aquisição da máquina "Finger joint", específica para a execução de uma das mais importantes etapas do beneficiamento da madeira.

Objetiva-se, com a presente pesquisa, apresentar a importância da Engenharia do produto para a potencialização das exportações, sendo que mais especificamente, busca-se analisar a visão de alguns dos mais pesquisados autores sobre o assunto, realizar uma abordagem sobre o produto e a exportação e apresentar os resultados de um estudo de caso realizado em uma empresa madeireira do município de Ponta Grossa - PR. 
Pretende-se mostrar, portanto, em que medida a Engenharia do Produto é importante para o crescimento de uma empresa, especialmente no mercado internacional.

\section{O produto e a exportação}

Sabe-se que a exportação exige da empresa a tomada de decisões mais complexas em face das incertezas maiores do que as encontradas na comercialização interna, em parte compensadas por comunicações melhores e disponibilidade de dados sobre os mercados.

De acordo com Tookey (1997, p. 33) “a exportação envolve quatro componentes: o produto, os serviços, o investimento e conhecimentos. A empresa visa obter um retorno sobre a aplicação desses recursos no exterior" (1997, p. 33). Também pode ser observada uma série de outros elementos que podem aqui ser referenciados como fundamentais para a exportação como as facilidades oferecidas pela legislação vigente, a facilidade de relações com clientes internacionais, dentre outros.

Nota-se, em conformidade com o que disse Tookey (1997), que o ponto principal para o sucesso de uma empresa na área de exportação, é o produto, pois "a teoria econômica das vantagens comparáveis diz que cada nação se especializa na fabricação dos bens que produz com eficiência comparativamente maior, exportando-os e, por sua vez, importa os produtos que fabrica com menos eficiência." (MACEDO et. al, 1997, p. 159).

Inserindo-se no universo deste estudo, destaca-se que, detentor do maior potencial de madeiras tropicais do mundo, o Brasil participa com a insignificante parcela de cerca de $2 \%$ do comércio internacional destes produtos (MACEDO et al, 1997). Acredita-se que a participação ainda reduzida do Brasil no contexto mundial provém, sobretudo, da desorganização da comercialização de seus produtos, e da falta de uma engenharia que focalize, essencialmente, sua produção.

Nos dias atuais, o mercado externo apresenta-se promissor tanto para o aperfeiçoamento administrativo, como também para a melhoria da qualidade e adequação dos produtos em níveis compatíveis e concorrentes com os originários de outros países.

Para Garcia, “o exportar, no sentido literal do termo, deve representar a diluição de risco, por permitir o engajamento entre os tradicionais clientes internos com os de outros países" (2001, p. 26). 
Outro aspecto de grande relevância é a preocupação com as questões ambientais. Sabe-se que cada vez mais a tendência mundial é a busca pelo desenvolvimento sustentável. Para Ferreira apud Camargo (2003), os processos de transformação sociocultural-tecnológica que demoravam tempo, décadas, ou até mesmo séculos para se desenvolver, atualmente se revelam complexos e desafiadores em tempo praticamente instantâneo.

$\mathrm{Na}$ atualidade, sabe-se que a sociedade mundial enfrentará, daqui em diante, a difícil tarefa de forjar novas relações com o meio ambiente. O sucesso do desenvolvimento econômico, diga-se globalmente, dependerá da preservação ambiental em todos os seus aspectos.

Portanto, a necessidade de desenvolvimento de novas tecnologias visando a preservação e consequentemente a sustentabilidade dos bens naturais não-renováveis é uma missão característica do futuro, como é o caso da reciclagem e do aproveitamento de resíduos, visto no processo apresentado nesse estudo. Tecer essas considerações torna-se importante, pois além da qualidade exigida no produto pelas empresas do exterior, cada vez mais é percebida a exigência do mercado internacional com as questões ambientais.

\section{3. $O$ caso da Madeireira $X$}

O estudo de caso deu-se, de forma investigativa, em uma madeireira situada na cidade de Ponta Grossa, estado do Paraná, aqui denominada, ficticiamente, por "Madeireira X”, que, operando desde 1998, alcançou um real sucesso a partir da Engenharia de alguns de seus produtos, conquistando o mercado internacional - especialmente México, Chile e Nova Zelândia. Atualmente, a madeireira comporta $4.600 \mathrm{~m}^{2}$ de área coberta, o que demonstra o seu real crescimento.

Os principais produtos da madeireira são o "clear blocks" e "blanks", blocos de madeira que servem como matéria prima para a produção de molduras, forros, cercas, entre outros. Ambos os produtos são exportados, sendo que para o mercado interno só são vendidos os subprodutos do processo. De acordo com Martins (2001, p. 75), a produção de "clear blocks", apesar de ser derivada da indústria madeireira em geral, possui um processo produtivo mais elaborado, e que se utiliza de tecnologia mais avançada do que o convencional. 
É preciso esclarecer que para a fabricação do "clear blocks" é preciso que as toras de Pinus taeda sejam transformadas em pequenos blocos de madeira, que devem ser aplainados, secos, e que não apresentem nós ou defeitos (MARTINS, 2001, p. 75). Já os "blanks" são "clear blocks" emendados longitudinalmente.

Para a produção dos produtos, a madeireira utiliza-se somente da espécie Pinus taeda, principal espécie das regiões Sul e Sudeste do País. Assim sendo, por se tratar os estados do Paraná e Santa Catarina os principais possuidores e florestas com esse tipo de Pinus, é nesta região que a indústria de "clear blocks" está concentrada (MORA, 2001).

Segundo o Instituto de Manejo e Certificação Florestal e Agrícola - IMAFLORA, “o estado do Paraná, é responsável por mais de $60 \%$ da produção nacional de "clear blocks"” (2004). Destaca-se que a Madeireira X optou pela espécie Pinus taeda por se tratar de uma madeira de grande aceitação no mercado internacional, além de ser uma espécie que foi plantada abundantemente na região dos Campos Grais, onde a cidade onde está sediada a madeireira localiza-se.

Em 2003, houve uma mudança no perfil da produção, devido à compra da máquina Finger joint, destinada, especialmente, à execução de uma das principais etapas no beneficiamento da madeira, o que alavancou a exportação dos produtos.

Em indicação resumida e aproximada, pelos valores da produção da indústria variarem muito pouco de um mês para o outro, depois da implantação da Finger joint para a execução de mais uma etapa no beneficiamento da madeira, pode-se ter os dados físicos da produção.

O gráfico a seguir demonstra os dados físicos da produção de clear blocks na empresa pesquisada.

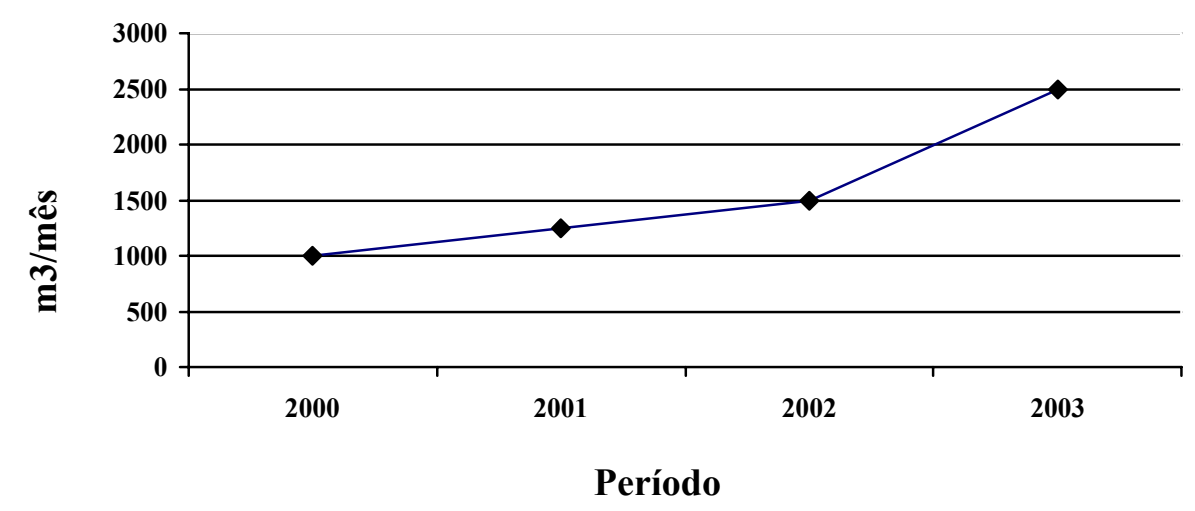


Gráfico 1: Dados físicos da Produção de clear/blocks na Madeireira X.

Totalizando tais dados físicos, vê-se que a produção da madeireira é intensa, com destaque para o fato de que, após a utilização da Finger joint, houve um aumento do volume de madeira final produzida.

\section{Finger joint}

O processo de finger-jointing (em português: "junta através de dedos"), mais do que uma exigência do mercado consumidor, surgiu devido à necessidade dos produtores de otimizar a matéria-prima, que antes era simplesmente queimada na caldeira.

"Muitas vezes pequenos pedaços de madeira alocados entre nós ou outros defeitos, podem ser reaproveitados se individualizados e juntados novamente, de onde se pode ainda produzir outros produtos adequados a esta qualidade" (PLACAGE, 2003).

Por meio deste desta etapa, os blocos de madeira mantêm a junta aparente, muito bem aceitos por mercados como o europeu, onde há uma valorização "ecológica" de produtos fabricados com este tipo de madeira, já que utiliza-se matéria-prima "recuperada", atitude politicamente e ecologicamente correta, tanto para o consumidor quanto para o produtor.

Quanto ao gráfico acima apresentado, destaca-se que "linhas automáticas para juntas na lateral podem atingir capacidades de até 120 peças juntadas por minuto. A produtividade das linhas que possibilitam o trabalho em ambos os sentidos (lateral e aparente) dependerão das características dos blocos a serem juntados, e normalmente são expressas em ciclos/min" (PLACAGE, 2003).

\section{Considerações Finais}

Com este estudo, pôde-se identificar a importância da Engenharia do Produto para o sucesso de uma organização que tem a pretensão de exportar. Isso porque, os mercados internacionais, mais exigentes que os nacionais, com maior demanda de produtos e ofertas, mostra-se bastante crítico no momento de importar. 
No caso da Madeireira X, da cidade de Ponta Grossa, Estado do Paraná, a expansão internacional de seus negócios, deu-se a partir do momento em que se adotou uma etapa intermediária no beneficiamento da madeira, que antes não acontecia, por meio da compra de uma nova máquina, a Finger joint.

Destaca-se que, com esta máquina, houve uma crescente redução do desperdício de matéria-prima, que no caso é o Pinus taeda, encontrado principalmente nos estados do Paraná e Santa Catarina, aumentando a produção de "clear blocks" e "blancks", seus produtos de exportação.

Vê-se, então, que houve uma mudança no perfil da produção, devido à aquisição da máquina "Finger joint", específica para a execução de uma das mais importantes etapas do beneficiamento da madeira.

No campo ambiental, de acordo com as palavras de Zacchi e Van Bellen (2005), a transformação dos processos de produção e a alteração da sua estrutura e de seus métodos de funcionamento exigem de todos os indivíduos um posicionamento que se possa considerar ambientalmente correto, fazendo com que os insumos utilizados, não gerem impactos ambientais e socioculturais.

Pôde-se demonstrar, por meio deste estudo, como a Engenharia do Produto é importante para o crescimento de uma empresa, que, no caso da madeireira $\mathrm{X}$, desenvolveu-se rapidamente: de uma pequena madeireira, passou, em pouco tempo, a uma expressiva exportadora.

\section{Referências}

CAMARGO, Ana Luiza de Brasil. Desenvolvimento sustentável: dimensões e desafios. Campinas: Papirus, 2003.

GARCIA, Luiz Martins. Exportar: rotinas e procedimentos, incentivo e formação de preços. 7. ed. São Paulo: Aduaneiras, 2001.

INSTITUTO DE MANEJO E CERTIFICAÇÃO FLORESTAL E AGRÍCOLA IMAFLORA. São Paulo, 2001. Disponível em <http://www.imaflora.org/> Acesso em 21 jan. 2004. 
MACEDO, Angela Regina Pires et all. Produtos sólidos de madeira. In: BNDES Setorial, Rio de Janeiro, ed. Esp., p. 157-176, out. 1997.

MARTINS, V. Indústria de clear blocks no Paraná: análise da competitividade diante da globalização e das mudanças estruturais ocorridas na década de 90. Florianópolis, 2001. 128p. Dissertação (Mestrado) - Universidade Federal de Santa Catarina.

MORA, Admir Lopes et al. Efeito do espaçamento de plantio em reflorestamentos de pinus taeda em Jaguariaíva - PR. In: Revista Uniandrade, v. 2, n. 2, pp. 213-223, jun. 2001.

PLACAGE. São Paulo, 2003. Disponível em <http://www.placage.com.br/> Acesso em 12 mar. 2004.

TOOKEY, Douglas. Técnicas de exportação. São Paulo: Melhoramentos, 1997.

ZACCHI, Giancarlo Philippi; VAN BELLEN, Hans Michael. O desenvolvimento sustentável e a organização do espaço regional. In: Diálogos \& Ciência, ano III, n. 5 , jun. 2005. Disponível em <http://www.ftc.br/revistafsa $>$ Acesso em 02 mar. 2006. 